\title{
A Comparison Of Student Performance In An Online Introductory Accounting Course With Traditional Classroom Students
}

\author{
Charles T. Stivason, Marshall University \\ Gary Saunders, Marshall University \\ Jean B. Price, Marshall University
}

\begin{abstract}
Use of e-courses in higher education has become increasingly widespread in recent years. Educators continue to debate the effectiveness of the technology and some argue that e-courses may be appropriate for some courses, but not for others. Each discipline must determine the effectiveness of e-courses consistent with its own priorities. Within accounting education, no consensus has been reached. Recently, an opportunity to compare student performance in an ecourse setting with that in a traditional classroom setting presented itself. A professor taught the introductory accounting course in the two settings; classes were conducted in such a way that student performance could be compared. This paper describes results and conclusions drawn from the comparisons.
\end{abstract}

\section{INTRODUCTION}

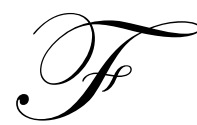

or decades, collegiate education has been offered through a variety of methods that allow students to complete courses without ever being in the same room as their professors. Years ago, students could take correspondence courses conducted by sending paper through the mail. Distance learning became somewhat more personal with the use of television broadcasts. In that setting, students in remote areas experienced the courses at the same time as those students who were actually in the same room as the instructor. With refinements of this technology, students participating in a course using distance learning could interact with the teacher, and the teacher could actually see the students in the various locations.

During the 1990s, developments in technology offered a new delivery vehicle for distance learning courses. Using the Internet, previous time and space constraints ceased to be a problem. Students and instructors could engage in the learning process in real time without the cumbersome television connections and other paraphernalia required by earlier distance learning methods. Over the Internet, a student anywhere in the world who had a computer and an Internet connection could now complete an electronic course (e-course) and easily communicate with his or her instructor.

E-courses represent an even greater departure from the traditional learning model than previously available distance learning methodologies. When e-courses were first developed, some thought they were just a passing fad, and others took action to explore new possibilities. Discussions among educators in various fields arose. In fact, many of the issues raised continue to be a source of debate. At the time, consequences of using this approach could not have been fully anticipated.

Given the challenges that use of the Internet courses presented, one might have expected colleges and universities to proceed cautiously and test carefully before offering e-courses. To the contrary, many schools were quick to begin offering e-courses. The 1993 Peterson's College Guide listed 93 "cyberschools" (Vasarhelyi and Graham 1997). By 1998, approximately 1,680 institutions were offering about 54,000 e-courses with 1.6 million students enrolled (Crow 2005). The American Federation of Teachers $(2001,37)$ indicated that "Distance education 
is one of the fastest-growing developments in higher education. Seventy percent of the nation's 4,000 two- and four-year colleges offered online courses in 2000, up from 48 percent in 1998."

Some institutions have gone farther, offering full degree programs online. According to Sausner $(2004,61)$, "Independent researchers at Market Data Retrieval found that 55 percent of the 5,500 accredited two- and four-year IHEs surveyed offer accredited degrees online, only a slight increase from the 54 percent in 2003; 47 percent offered degrees online in 2002." The survey also found that many other universities offer course work online but do not offer degrees online.

In the fall of 2004, results of another survey of academic leaders from more than 1,100 colleges and universities indicated continued growth in online learning. At that time, "about 2.6 million U.S. college students are taking courses online this fall, and enrollments in such courses are rising at rates faster than overall college enrollment" (Trotter 2004, 16). By 2005 it is expected to be a $\$ 46$ billion business. The term "business" would seem appropriate because, in addition to traditional nonprofit universities, many for profit businesses have sprung up to take advantage of the money making potential offered by the growth in distance learning.

Issues related to online learning are particularly relevant to business professors. According to Phipps $(2004,36)$ "the percentage of faculty teaching distance education is higher in the program area of business compared to the fine arts, humanities, and the natural sciences." Clearly, accounting professors and all educators in business programs must be aware of today's changing educational environment.

Is this new environment being welcomed by students? Have their needs been met? The Sloan Consortium surveyed the chief academic officers at institutions offering online classes and reported that " 40.7 percent of schools with online offerings agreed or strongly agreed with the statement that students are at least as satisfied with online courses as they are with face-to-face offerings. Only three percent of all schools with online offerings disagree with the statement, with the remaining portion (56.2\%) neutral" (Sloan Consortium 2004, 10).

A limited amount of information is available relative to students' reactions to taking accounting courses online. A recent survey by Basile and D'Aquila (2002) investigated attitudes of introductory accounting students and results indicated that students in e-courses had similar attitudes to those in the traditional classroom.

If students are satisfied with e-courses and educational institutions are finding them to be profitable, it is safe to say that use of the Internet as an educational delivery vehicle will most likely continue to expand. Many concerns about e-courses have been voiced and, in most cases, faculty opinions about such issues vary widely. One concern should, however, be universal: Is learning achieved as effectively in e-courses as it is in courses offered in a traditional setting? This study is one effort to answer that question.

\section{THE STUDY}

Recently, an accounting professor taught three sections of an introductory accounting course in two different learning environments - online and classroom. Two of the sections were taught in the traditional classroom setting and one section was taught online. This situation provided an opportunity to compare the performance of students enrolled in the sections taught in the traditional classroom with that of an online section of the course. At the same time, the impact of different testing methods could be evaluated. Performance could be compared with a number of different testing methods.

The assignment of students to each section, 2 in-class sections and 1 online section, was self selection. While this is not completely random, no other assignment process was available.

Quizzes and exams were both given in a time-controlled environment and in a two-day take-home environment. Additionally, students in the online course had access to the book and other aids for all of the assignments while the traditional students had these aids only for the take-home assignments. 
Efforts were made to assure that students in the two learning environments had access to same resources. The notes used in the traditional classroom were posted on WebCT for the online students and PowerPoint slides were made available to both groups of students. One issue often raised in the debate over the two learning environments is the interaction and discussion occurring in the classroom setting. In an effort to facilitate similar interaction and discussion within the online group, those students were required to post comments to an electronic bulletin board. Traditional office hours were offered for the classroom students, while office hours for the online students were held using a chat room in WebCT.

A number of students did not complete the course and the results presented below only include data from students who completed the course and both exams. Thirty one students enrolled in each of the traditional sections and 22 registered for the online section. In the traditional classroom sections, 8 students in each section withdrew leaving 23 in each section that completed the course. Six students withdrew in the online course and 16 completed the course. The withdrawal rates for the different course presentation formats were similar.

Both groups of students (classroom and online) were given quizzes consisting of problems requiring calculations, analyses, or short answers. In the classroom, students were given six quizzes in-class with a 20-minute time limit and six quizzes given as take-home assignments with a 48 hour time limit. Similarly, online students were given the same quizzes with 20 minutes and 48 hour time limits. A major difference was that online students had access to the text, and possibly other aids, while the classroom students did not.

Two exams were given using a similar approach. One exam was given in a 75 minute time period and the other was a take-home exam with a 48 hour time limit. As with the quizzes, online students had access to aids that classroom students did not have.

Student performance in twelve quizzes and two exams provides the data for the comparisons made. If students missed a quiz, no grade was entered so that the average score was not unfairly impacted.

In a traditional classroom setting, students have very different experiences when they are tested in-class and when they are tested with a take-home assignment. On the other hand, in the online learning environment, unless specific controls are in place to limit a student's use of the text or other resources, there is little difference between "in-class" and the take-home assignment. So, in the online setting, the only difference in the two testing methods was the amount of time students had to complete the quizzes and exams while classroom students could use the text and aids only with the take-home assignments.

For the in-class quizzes given to the classroom students, the online students were given the same 20-minute limit. Results using this testing method will be referred to as " $20 \mathrm{~min}$." for the online students and "in-class" for the classroom students. Similarly, when classroom students were tested using take-home assignments, online students were also given 48 hours to complete the work. Results using this testing method will be called " $48 \mathrm{hr}$." for the online students and "take-home" for the classroom students.

To control for possible bias, relating to relative difficulty of the different quizzes, they were randomly assigned to the "in class" and "take home" groups. In a similar fashion, determination of which exam would be given in-class and which would be take-home was done randomly. The first exam of the semester was to be given as an in-class assessment, and the second exam was to apply a take-home approach. Both exams covered the same amount of material and were presented in multiple-choice format. The questions included problems as well as terms and concepts. When classroom students were given the in-class exam, online students were given the same 75minute time limit. Their results in this setting will be referred to as " 75 min." for online students and "in-class" for the traditional classes. When students in the classroom took the take-home exam, online students were given the same two days to complete their exam. Those results are shown as " $48 \mathrm{hr}$." for online students and "take home" for classroom students. 


\section{RESULTS}

Results for the two traditional sections were analyzed to determine if they could be treated as a single for purposes of comparisons with the online group. Performance in all four of the scenarios was compared using t-tests yielding no significant differences between the performance of the two in-class sections.

Comparisons of student learning, as measured by student performance on quizzes and exams, in the two learning environments offered some interesting results. Figure 1 shows the performance on 20 minute quizzes for students in the online class and those in the traditional classroom setting. Online students outperformed the traditional students by almost 14 percentage points, $80.4 \%$ to $66.7 \%$. However, this result is not surprising because online students had access to the textbook and other resources not available to the classroom students. Without specific controls to restrict online students' use of such resources, online students will always have this advantage, which appears to be worth about 14 percentage points.

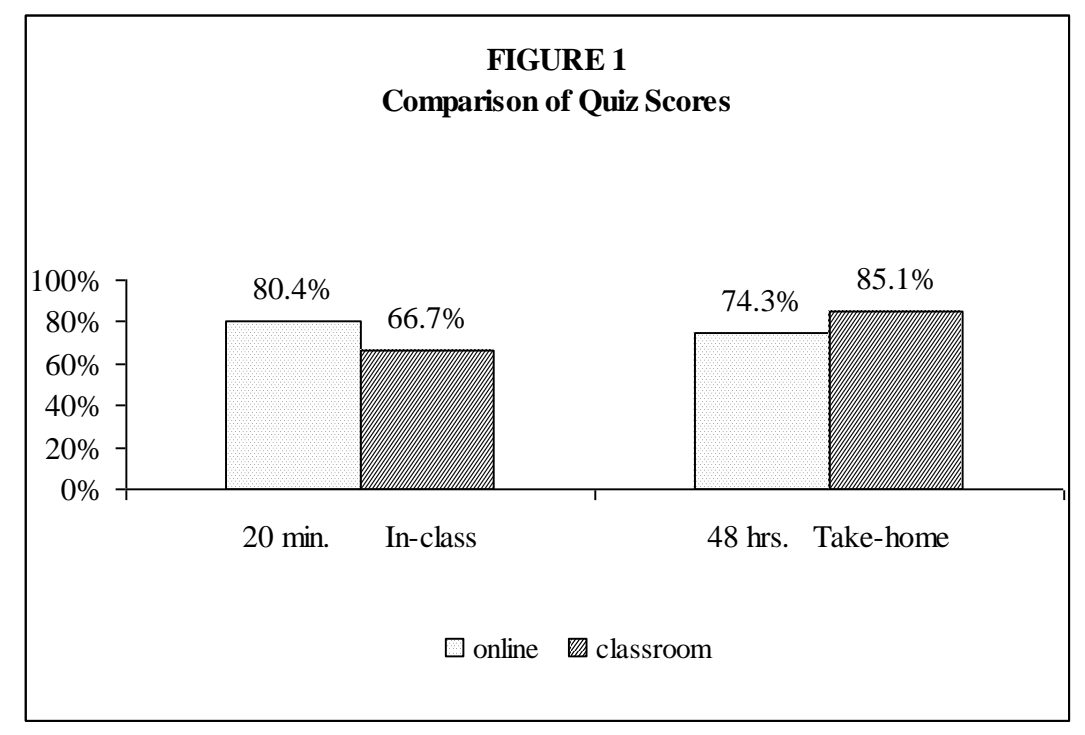

Figure 1 shows a different outcome when the two groups of students are given quizzes that can be completed over a 48-hour period. In this setting, both groups of students have unfettered access to books and other resources to help them complete the work. From the classroom students' perspective, the change in testing method was significant. Indeed, access to resources is a major departure from traditional in-class testing and the online students had access to resources under both testing methods. Interestingly, as a group, performance of the online students was lower when they were given an extended amount of time to complete the quizzes. Classroom students averaged $85.1 \%$ while the online students averaged only $74.3 \%$ on this set of quizzes. This $11 \%$ stronger performance by the classroom group in this setting may be a result of interaction among the students, both inside and outside of class. Of course, a second possibility is that the traditional, in-class, environment is a better learning environment. In most cases, a classroom setting produces much more collaboration among students than is typically found in an online learning environment.

Impact of learning environments and testing methods were also explored in the context of two exams. Two multiple-choice exams were given to both the online students and those in the traditional classroom. WebCT was used to administer the exams online. In this setting, order of information was randomized by WebCT so that each exam was unique. The first exam was administered in-class, during a 75-minute class period; online students were given a 75-minute time limit as well. The second exam was given to the classroom students as a take-home exam, while a 48-hour time limit was imposed on the online students. 
Exam score results are shown in Figure 2. Similarities between Figure 1 and Figure 2 are obvious. The same factors that affected student performance on the quizzes appear to be present in the exam scores as well. On the left side of Figure 2, results from the in-class and 75-minute exams are consistent with those from the in-class and 20-minute quizzes. Students online outscored those in the classroom. The online students averaged $62.8 \%$ and the classroom students averaged only $53.8 \%$. This result was expected since the online students again had access to additional resources during the test.

When the exam was given as a take-home assignment, results were consistent with those from the takehome quizzes. As illustrated on the right side of Figure 2, the average score for the students in the classroom was $69.9 \%$ while the online students averaged only $63.4 \%$. As with the take-home quizzes, this outcome may be a result of collaboration among the students. By the end of the semester, most classroom students had the opportunity to establish relationships with fellow students, and interaction during the 48 hours would not be unexpected. Interestingly, traditional student outscored online students by only $6.5 \%$, down from the almost $11 \%$ better performance on the take-home quizzes. Perhaps online students were more serious about the exams than they were about the quizzes.

An interesting note is that the relative advantage to online students from using aids declined from approximately 14 percentage points on the timed quizzes to about $9 \%$ on the timed exam. Perhaps this difference reflects a more serious attitude about the exam, compared to the quizzes, on the part of the in-class students or, a less serious attitude by online student since they have aids on the exam.

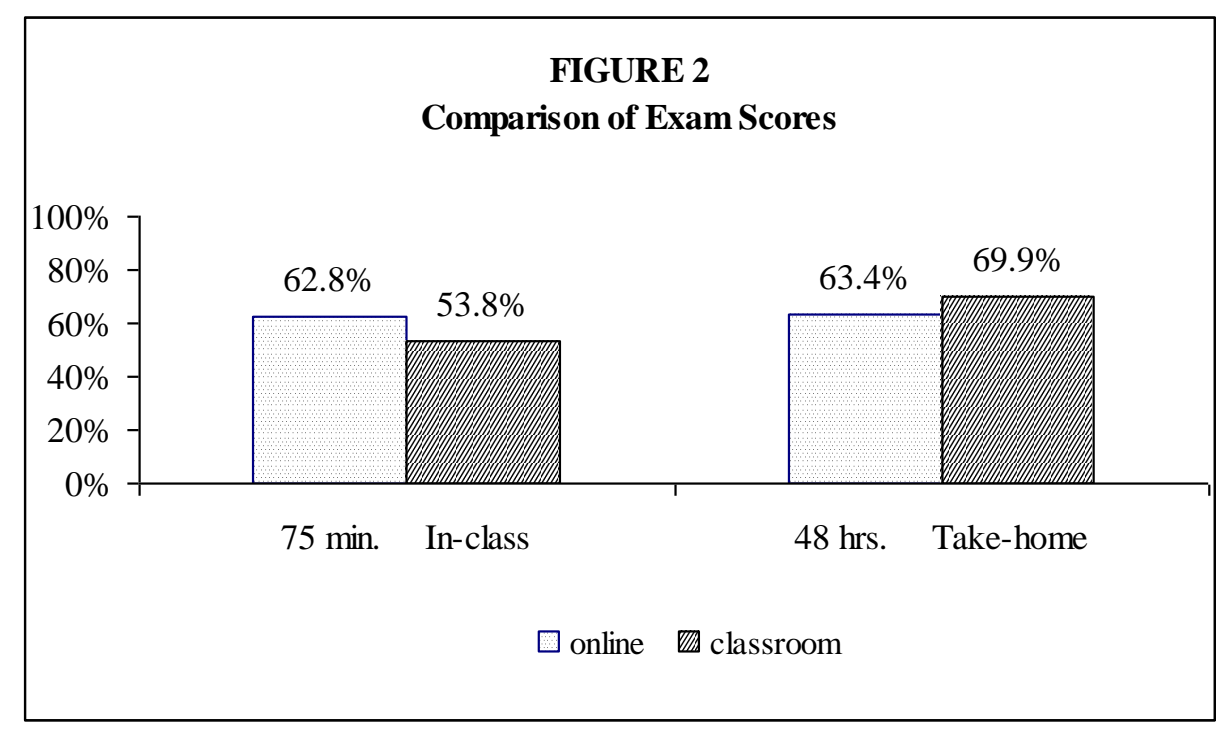

Figure 3 shows average grades for each set of quizzes and exams, and the number of each graded assignment used in the study. The exam scores reported in Figure 3 are the number of points awarded out of 40. The average quiz scores reported below are the number of points earned out of 20 . T-tests were performed to compare the averages. Even though online students outscored the classroom students by about $9 \%$, the average exam scores were not significantly different at a level of 0.05 . However, the advantage to online students for the quizzes was a significant advantage as the average quiz scores for the two learning environments were significantly different $(\mathrm{p}=0.0002)$.

When the environment shifted to take-home quizzes traditional classroom students performed significantly better than online students at the 0.002 level. These results indicate that when one group (online students) is given an advantage on taking quizzes that they outperform in-class students but when the groups are on equal footing 
traditional students outperform online students. When taking exams, either on equal or unequal footing, the performance of the two groups was not significantly different.

Next, t-tests were performed to determine if scores from each student group (online and classroom) differed when the testing method changed. Figures 1 and 2 showed the classroom students scored higher on take-home assignments than they did when tested in-class. T-tests would determine if the difference in scores was statistically significant. The results are reported in Figure 4. The differences resulting from the change of testing method for the classroom students are significant for both the quizzes and exams.

\begin{tabular}{|c|c|c|c|c|c|}
\hline \multicolumn{6}{|c|}{ FIGURE 3} \\
\hline \multicolumn{6}{|c|}{ Average Exam and Quiz Scores } \\
\hline & & \multicolumn{2}{|c|}{ In-class / 20 or $75 \mathrm{~min}}$. & \multicolumn{2}{|c|}{ Take-home / 48 hrs. } \\
\hline & & Exam & Quizzes & Exam & Quizzes \\
\hline \multirow{2}{*}{ Online } & Scores & 25.1 & 16.1 & 25.4 & 14.9 \\
\hline & $\mathrm{N}$ & 16 & 81 & 16 & 74 \\
\hline \multirow{2}{*}{ Classroom } & Scores & 21.5 & 13.3 & 28.0 & 17.0 \\
\hline & $\mathrm{N}$ & 46 & 247 & 46 & 261 \\
\hline \multicolumn{2}{|c|}{ Online vs Classroom T-test } & 0.0689 & 0.0002 & 0.1260 & 0.0002 \\
\hline
\end{tabular}

Next, t-tests were performed to determine if scores from each student group (online and classroom) differed when the testing method changed. Figures 1 and 2 showed the classroom students scored higher on take-home assignments than they did when tested in-class. T-tests would determine if the difference in scores was statistically significant. The results are reported in Figure 4.

\begin{tabular}{|l|c|c|c|}
\hline \multicolumn{3}{|c|}{ FIGURE 4 } \\
\hline \multicolumn{4}{|c|}{ Comparison of Scores by Classes } \\
\hline & In-class / 20 or 75 min. & Take-home / 48 hrs. & T-tests for comparison of sets \\
\hline Classroom Exams & 21.5 & 28.0 & 0.00001 \\
\hline Classroom Quizzes & 13.3 & 17.0 & 0.00000 \\
\hline \multicolumn{3}{|c|}{} \\
\hline Online Exams & 25.1 & 25.4 & 0.90482 \\
\hline Online Quizzes & 16.1 & 14.9 & 0.16160 \\
\hline
\end{tabular}

Classroom students benefited significantly, 0.00001 for exams and 0.00000 for quizzes, from being allowed to take the exam or quiz as a "take home." The use of the text, and other resources, may be the major factor in this improvement. However, t-tests performed on scores from the online students indicate no significant difference in performance when the testing method changed. In the online learning environment students had access to additional resources for both testing methods and the additional time did not appear to improve performance significantly.

\section{CONCLUSIONS}

E-courses appear to be here to stay. This study explores how testing in an online environment compares to that of the traditional classroom. It was no surprise that the online students performed better on their graded assessments than the traditional classroom assessments when timed, in-class testing was used because online students had access to the text and other aids. Unless this inequity is removed online students may be assigned inflated grades. This advantage is not as apparent when only online sections are being taught without in-class sections for comparison. Adjusting grades downward to compensate for this advantage is probably not wise. However, it is probable that, without some adjustment, online students may be assigned inflated grades and proceed through introductory accounting courses without the requisite knowledge. 
Proctoring of online assessments could eliminate some of the problems encountered, particularly the unfair resources available for the tests. However, this was not permissible in the study since university policy did not permit the restrictions on online students that this required. Since one of the attractions of online learning is the possibility of having students from all parts of the world taking e-courses, on-campus proctoring does not appear to be a viable solution for many institutions.

Performance scores on the online assessments did not improve significantly when students were given extended time to complete the work and, in fact, actually declined on quizzes of online students. This is an interesting finding since one of the problems encountered in the online learning environment is internet connection problems when students are given only a short time frame to complete the assessment. Our results indicate that additional time allowed on the online assignments will not improve the grades.

One result of interest is that when in-class students were given equal footing (text and other resources) with online students on take-home assignments they performed better. On quizzes they performed almost $11 \%$ better and on quizzes over $6 \%$ better. This could be due to the better networking by the in-class students in developing relationships with fellow students through the class meetings and collaboration on the assessments. On the other hand, perhaps it is evidence that the in-class setting is a superior learning environment for the typical student because, when students were given access to additional resources traditional students outperformed online students. Previous studies have suggested that in order to be successful, online students must be more self-motivated and dedicated than the typical in-class student.

In general, faculty members must be aware of the impact of the choice of instructional environment. Results suggest that the difficulty of the assignments should be greater than that of traditional in-class assignments, but don't need to be as challenging as take-home assignments. Also, perhaps the use of take-home exams should be utilized more often with students in the traditional classroom setting to offset any advantage that online students might have.

\section{REFERENCES}

1. American Federation of Teachers, New AFT Report Proposes Standards for ONLINE programs, Black Issues in Higher Education, Vol. 18, Issue 1, p37, March, 1, 2001.

2. Basile, Anthony \& D'Aquila, Jill M., An Experimental Analysis of Computer-Mediated Instruction and Student Attitudes in a Principles of Financial Accounting Course, Journal of Education for Business, Jan/Feb 2002, Vol. 77, Issue 3, p 137-144.

3. Crow, Galen B., The End of the University as We Know It? Enabling Higher Education through Technology, http://www.cat.ilstu.edu/publications/text.shtml, 2005

4. Phipps, Ronald, National Postsecondary Education Cooperative. How Does Technology Affect Access in Postsecondary Education? What Do We Really Know? (NPEC 2004-831), prepared for the National Postsecondary Education Cooperative Working Group on Access-Technology. Washington, DC: 2004.

5. Sloan Consortium, Entering the mainstream: the quality and extent of online education in The United States, 2003 and 2004, http://www.sloan-c.org/resources/survey.asp, 2004.

6. Sausner, Rebecca, What Happened to e-Learning and Why? University Business, Vol. 7, Issue 11, November 2004.

7. Trotter, Andrew, Online Education, Education Week, Vol. 24, Issue 13, p 16, November 24, 2004.

8. Vasarhelyi, M.A., \& Graham, L., Cybersmart: Education and the Internet, Management Accounting, August, 1997, p 32-36. 
NOTES 